\title{
Capsule Commentary on Bennett et al., Engaging Stakeholders to Inform Clinical Practice Guidelines that Address Multiple Chronic Conditions
}

\author{
Miquel À. Mas, MD \\ Department of Geriatric Medicine and Palliative Care, Badalona Serveis Assistencials, Badalona, Catalonia, Spain.
}

J Gen Intern Med 32(8):918

DOI: $10.1007 / \mathrm{s} 11606-017-4080-4$

(c) Society of General Internal Medicine 2017

B ennett and colleagues present an innovative patientcentered research methodology engaging multiple stakeholders, including groups of patients and caregivers, to adapt clinical practice guidelines (CPG) to patients with multiple chronic conditions (MCC). The authors used a modified Delphi method to identify key topics in order to translate them into relevant questions for people with MCC. ${ }^{1}$

Despite several limitations of this qualitative study, including the use of a sample of potentially motivated selected patients, or predefining the list of high-priority topics from a program without patient-stakeholder input, and allowing only two final topics to be identified by participants ('optimal blood pressure goals' and 'diabetes medication management'), we can learn from this experience by understanding contextual factors of health and care priorities for people with MCC. ${ }^{2}$

The most relevant outcomes identified from the study could be classified based on several categories: self-perception of health status (as physical function and energy or emotional health and well-being), treatment effects (as avoidance of treatment burden, side effects and risks), health care system navigation (including communication and coordination) and prevention of adverse long-term health outcomes. Some of these structural aspects of care were considered key elements of high-quality primary care for vulnerable elders in previous research. ${ }^{3}$

This approach supports the notion that focusing on patients' priorities and making decisions based on patients' views, not on diseases, is possible ${ }^{4}$ not only in clinical settings, but also in the translation of evidence-based medicine to the care of people with MCC. ${ }^{5}$

With this study, the authors have opened the door to new evidence perspectives in the field of MCC care by including patients' perceptions in the methodology of developing CPGs. This approach should be replicated in future CPG development, with implications for evidence reviewers, CPG developers, researchers, clinicians and policymakers worldwide.

Corresponding Author: Miquel À. Mas, MD; Department of Geriatric Medicine and Palliative CareBadalona Serveis Assistencials, Badalona, Catalonia, Spain (e-mail: drmqagmas@gmail.com).

\section{Compliance with Ethical Standards:}

Conflict of Interest: The author has no conflicts of interest with this article.

\section{REFERENCES}

1. Bennett WL, Robbins CW, Bayliss EA, Wilson R, Tabano H, Mularski RA, Chan WV, Puhan M, Yu T, Leff B, Li T, Dickersin K, Glover C, Maslow K, Armacost K, Mintz S, Boyd CM. Engaging stakeholders to inform clinical practice guidelines that address multiple chronic conditions. J Gen Intern Med. doi:10.1007/s11606-017-4039-5

2. Bayliss EA, Bonds DE, Boyd CM, et al. Understanding the context of health for persons with multiple chronic conditions: moving from what is the matter to what matters. Ann Fam Med 2014;12(3):260-9.

3. Ganz DA, Fung CH, Sinsky CA, Wu S, Reuben DB. Key elements of highquality primary care for vulnerable elders. J Gen Intern Med. 2008; 23(12):2018-23.

4. Tinetti ME, Esterson J, Ferris R, Posner P, Blaums CS. Patient prioritydirected decision making and care for older adults with multiple chronic conditions. Clin Geriatr Med. 2016; 32(2):261-75.

5. Tinetti ME, Bogardus ST, Agostini JV. Potential pitfalls of diseasespecific guidelines for patients with multiple conditions. N Engl J Med 2004; 351(27):2870-4. 